Adıyaman Üniversitesi Sağlık Bilimleri Dergisi, 2020;6(3):273-278

doi:10.30569.adiyamansaglik.591181

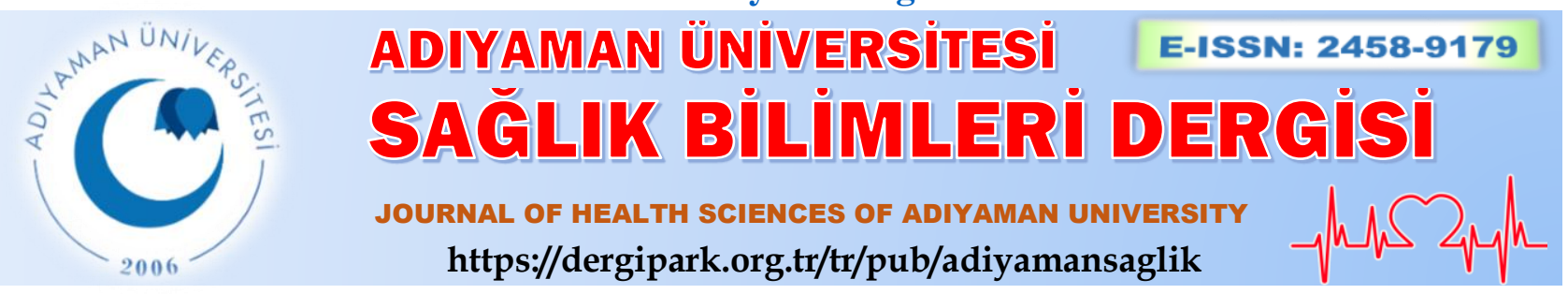

Özgün Araştırma/Research Article

\title{
Yumuşak kontakt lens kullanıcılarında korneal değişikliklerin incelenmesi
}

\section{Investigation of corneal changes in soft contact lens wearers}

\author{
Mübeccel BULUT 1 @(D), Abdurrahman BİLEN ${ }^{2}$ (D), Ayşe Sevgi KARADAĞ $\breve{C}^{(D)}$ \\ ${ }^{1}$ Şanlıurfa Siverek Devlet Hastanesi, 63600, Şanlıurfa-Türkiye \\ ${ }^{2}$ Adıyaman Üniversitesi, Tıp Fakültesi, Göz Hastalıkları Anabilim Dalı, 02040, Adıyaman-Türkiye
}

Atıf gösterme/Cite this article as: Bulut M, Bilen A, Karadağ AS. Yumuşak kontakt lens kullanıcılarında korneal değişikliklerin incelenmesi. ADYÜ Sağllk Bilimleri Derg. 2020;6(3):273-278. doi:10.30569.adiyamansaglik.591181

$\ddot{O} z$

Amaç: Kontakt lens kullanan hastalardaki korneal değişimlerin incelenmesi.

Gereç ve Yöntem: Kontakt lens kullanmak için başvuran 18 olgunun, topografi cihazı ile ölçülen merkezi korneal kalınlık (MKK) ve keratometri değerleri (K1, K2), speküler mikroskop cihazı kullanılarak elde edilen kornea endotel değerleri ve schirmer testi sonuçları kaydedildi.

Bulgular: Çalışmaya 18 hastanın 36 gözü dâhil edildi.

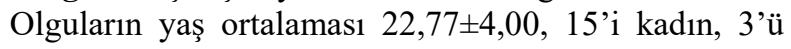
erkekti. K1, K2, MKK ve endotel sayıs1 değerlerinde lens kullanımı sonrası anlamlı bir azalma olduğu görüldü. $(p<0,05)$ Posterior K1 değerinde lens kullanımından sonra anlamlı bir artış olduğu görüldü. Sonuç: Silikon hidrojel lensler yüksek oksijen geçirgenliğine rağmen korneanın fizyolojisi ve mimarisini hala etkileyebilmektedir.

Anahtar Kelimeler: Kontakt lens; Kornea; Topografi.

\begin{abstract}
Aim: Investigate corneal changes in patients who use contact lenses.

Materials and Methods: 18 patients included in this study. Central corneal thickness and keratometry measured by topography, corneal endothelial values obtained using specular microscope and Schirmer results were recorded.

Results: The mean age was $22.77 \pm 4.00$. 15 patients were female, 3 male. K1, K2, CCT and endothelial cell count levels showed decreases after lens use $(p<0.05)$. An increase was observed in posterior K1.

Conclusion: Despite their high oxygen permeability, silicone hydrogel lenses still affect the physiology and architecture of the cornea.

Keywords: Contact lens; Cornea; Topography.
\end{abstract}

Yazışma Adresi/Address for Correspondence: Mübeccel BULUT, Şanlıurfa Siverek Devlet Hastanesi, 63000, Şanlıurfa-Türkiye, E-mail: mubeccelbagdas@ gmail.com

Geliş Tarihi/Received:12.07.2019 Kabul Tarihi/Accepted:25.08.2020

Yayım Tarihi/Published online:03.12.2020

Bu eser, Creative Commons Atıf-GayriTicari 4.0 Uluslararası Lisansı ile lisanslanmıştır. Telif Hakk1 @ 2020 Adıyaman Üniversitesi Rektörlüğü 


\section{Giriş}

Kontakt lensler kırma kusurlarının düzeltilmesi amaciyla 19. yüzyıldan beri kullanılmaktadır. Önce cam materyalden kontakt lensler, sonra sert kontakt lensler, daha sonrada yumuşak kontakt lensler kullanılmıştır. ${ }^{1,2}$

Sert kontakt lensler, gaz geçirmeyen (PMMA; Polimetilmetakrilat) ve gaz geçirgen (CAB; Selüloz asetat bütirat, silikon akrilatlar ve saf silikon polimerleri) olmak üzere ikiye ayrılır. PMMA, kontakt lensler için kullanılan ilk materyaldir. Dayanıklı, şeffaf ve 1slanabilirliği yüksektir. Bunlarla beraber hipoksi gibi bir dezavantajı olduğu için günümüzde pek tercih edilmemektedir. $\mathrm{CAB}$ ise gaz geçirgendir fakat dayanıksızdır ve 1slanabilirliği düşüktür. Silikon akrilatlar en çok kullanılan rijid gaz geçirgen lenslerdir. PMMA'nın optik şeffaflığına silikonun oksijen geçirgenliği eklenmiştir., ${ }^{3,4}$

Yumuşak kontakt lensler, hidrojel ve silikon hidrojel lenslerdir. Hidrojel lenslerin en önemli özelliği su tutucu olmalarıdır. Bu özellik materyalin oksijen geçirgenliği, elastikliği, 1şı̆̆ kırma gücü ve gerilmeye karş1 dayanıklılığını sağlar., ${ }^{5,6}$ Silikonun yüksek oksijen geçirme özelliği ile hidrojelin yüksek su tutma özelliği birleştirilerek silikon hidrojel lensler üretilmiştir. Lotrafilcon A ve Balafilcon A tanımlanan ilk silikon hidrojel lenslerdir. $^{2}$

Kontakt lensler hipoksik bir ortam oluşturarak kornea metabolizmasını olumsuz etkiler. ${ }^{1}$ Kornea normal şartlarda oksijen ile metabolik ihtiyacını sağlarken, hipoksik ortamda anaerobik glikoliz yaparak laktik asit biriktirir. Laktik asit stromal ödeme ve keratosit fonksiyonlarında bozulmaya böylece korneanın fizyolojisi ve mimarisinde etkilenmelere yol açar. Gece, normalde \%3-4 oranında olan kalınlaşma, geleneksel hidrojel lenslere geçildiğinde \% $\%$, gaz geçirgen lenslere geçildiğinde $\% 5$ olarak bulunmuştur. ${ }^{2,7,8}$ Fonn ve ark. bu oranı silikon hidrojel lenslerde $\% 2,5$, hidrojel lenslerde $\% 8,4$ olarak bulmuştur. ${ }^{9}$

2000'li yıllarda yüksek oksijen geçirgenliğine sahip silikon hidrojel kontakt lenslerin kullanıma girmesi ile bu etkiler minimalize edilmiştir. Çalışmalarda hidrojel kontakt lens kullanımı ile görülen kornea epitelinde incelme, mikrokist oluşumu, limbal hiperemi ve vaskülarizasyon, stromal incelme ve endotel morfolojisinin değişimi gibi hipoksik bulguların silikon hidrojel lenslerde olmadığ 1 görülmüştür. ${ }^{10,11}$

Silikon hidrojel lenslerde modulus hidrojel lenslere göre yüksektir. Yüksek moduluslü lensler kornea ve konjonktiva yüzeyine tam oturmazlar, özellikle midperiferde belirgin olmak üzere değişken aköz faz profili oluştururlar ve kapak basıncını daha fazla yansitırlar. Koruyucu musin tabakasinın etkilenmesi ve lens epitel arasındaki temas sonucu epitelde hasarlanma meydana gelir. ${ }^{2,12}$

2005 y1lından itibaren ilk nesil silikon hidrojel lenslere göre su içeriği fazla ve modulusu daha düşük yeni nesil silikon hidrojel lensler geliştirilerek epitele olan olumsuz etkilerin azaltılması hedeflenmiştir. Galyfilcon A, Senofilcon A, Lotrafilcon B, Comfilcon A, Asmofilcon A, Enfilcon A ilk silikon hidrojel lenslere göre yüksek su içerikli olması nedeni ile düşük oksijen geçirgenliğine ve düşük modulusa sahiplerdir. ${ }^{13}$

Çalışmamızda refraksiyon kusuru nedeni ile kontakt lens kullanan hastalardaki korneal değişimlerin incelenmesi amaçlanmıştır.

\section{Gereç ve Yöntem}

Çalışmamızda kliniğimiz kontakt lens biriminde kayıtlı, kontakt lens kullanmaya ilk kez birimimizde başlayan 18 olgunun 36 gözü retrospektif olarak değerlendirildi. Çalışma öncesi 2018/9-10 karar say1lı üniversitemiz etik kurul onayı alınmıştır.

Çalışmaya 18-40 yaş arası, refraksiyon kusuru nedeni ile ilk kez kontakt lens kullanmaya birimizde başlayan hastalar alındı. -4 diyoptriden fazla sferik, -1.5 den fazla silindirik refraksiyon değeri olanlar, oküler yüzey patolojisi olanlar, oküler travma ve cerrahi öyküsü olanlar dahil edilmedi.

Lensin 8-12 saat öncesinden çıkarılmış olmasına dikkat edildi.

Sirius ${ }^{\circledR} \quad$ kornealtopografi cihazi (Costruzione Strumenti Oftalmici, Floransa, 
İtalya) yardımı ile santral korneal kalınlık değerleri, Sim K1, Sim K2, posterior K1 ve K2 değerleri alınd. Diurnal etkiyi en aza indirmek için sabah aynı saatlerde çekimler alındı. Nidek Cem 530 nonkontakt speküler mikroskop cihazı kullanılarak elde edilen kornea endotel değerleri kaydedildi. Schirmer testi topikal anestezi kullanılmadan yapıldı ve kornea ile temas edilmemesine dikkat edilerek, konjonktival keseye lateral ve orta üçte bir bölümün birleşim yerine şerit yerleştirildikten sonra göz 5 dakika kapatıldı. Beş dakika sonra şeritteki ıslanma miktarı milimetre olarak kaydedildi. Hastalar 4 ay sonra kontrole çağrıldı. Kontrol değerleri ilk başvuru değerleri ile kıyaslanmak üzere kaydedildi.

\section{İstatistiksel analiz}

Çalışmanın verileri SPSS "Statistical Package For Social Sciences (SPSS17.0)" programı aracılığ 1 ile değerlendirildi. Yüzdelik hesabı, ortalama, standart sapma değerleri hesapland. Verilerin değerlendirilmesinde, niteliksel değişkenlerin karşılaştırmalarında ki-kare testi kullanıldı. Shapiro-Wilk test istatistiğine göre $(p<0,05)$ değişkenler normal dağılıma uygun olmadığından non parametrik test istatistiklerinden uygulama öncesi ve sonras1 değişkenleri karşılaştırmak için wilcoxon test istatistiği uygulandı. $p<0,05$ olarak anlamlı olarak kabul edildi.

\section{Bulgular}

Çalışmaya kontakt lens birimizde kayıtlı, düzenli olarak kontrollerine gelen 18 hastanın 36 gözü dâhil edildi. Olguların yaş ortalaması $22,77 \pm 4,00,15$ 'i kadın, 3'ü erkekti. Ortalama

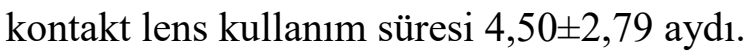

Hastaların kontakt lens kullanmak için ilk başvurdukları zaman çekilen topografi bulgularında, ort. (ortalama) K1 değeri $50,71 \pm 2,43 \mathrm{D}$, ort. K2 $52,29 \pm 2,37 \mathrm{D}$, ort. MKK (merkezi korneal kalınlık)

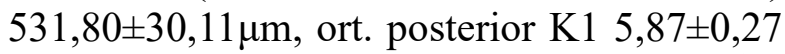
D, post. K2 6,40 $\pm 0,29$ D olarak belirlendi. İlk muayenedeki ort. schirmer test değeri $25,63 \pm 8,28$ 'di. İlk speküler mikroskopi bulgularında ise ort. endotel sayıs1 $204,25 \pm 56,59$, ort. endotel yoğunluğu $2842,41 \pm 261,99$, ort. değişkenlik katsayısı $25,83 \pm 3,67$, ort. hekzagonal hücre oran1 $68,47 \pm 5,50$ olarak belirlendi (Tablo 1). Hastalar 4 ay sonra kontrole çağrılmış olsa da kontrol zamanları 2-8 ay arasinda değişmekteydi ort. (4,5 ay). Hastaların kontrol değerleri ortalamaları ise; K1 49,96 $\pm 1,87 \mathrm{D}$, K2 51,64 $\pm 2,05$ D, MKK 529,02 $\pm 29,56 \mu \mathrm{m}$, post. K1 5,97 $\pm 0,02 \mathrm{D}$, post K2 $6,37 \pm 0,34 \mathrm{D}$, schirmer 22,52 $\pm 10,29$, endotel say1 $186,44 \pm 57,34$, endotel yoğunluğu $2846,02 \pm 273,55$, değişkenlik katsayıs1 $27,66 \pm 7,87$, hekzagonal hücre oran1 $67,13 \pm 4,62$ olarak belirlendi.

Tablo 1. Kontakt lens uygulama öncesi ve sonrası bulgular.

\begin{tabular}{lllll}
\hline & Uygulama öncesi & Uygulama sonras1 & $p$ & $z$ değeri \\
& Ortalama \pm standart sapma & Ortalama \pm standart sapma & & $-2,215$ \\
\hline k1 & $50,71 \pm 2,43$ & $49,96 \pm 1,87$ & $0,027^{*}$ & $-2,236$ \\
k2 & $52,29 \pm 2,37$ & $51,64 \pm 2,05$ & $0,025^{*}$ & $-1,962$ \\
mkk & $531,80 \pm 30,11$ & $529,02 \pm 29,56$ & $0,048^{*}$ & $-2,860$ \\
postk1 & $5,87 \pm 0,27$ & $5,97 \pm 0,02$ & $0,004^{*}$ & $-1,310$ \\
postk2 & $6,40 \pm 0,29$ & $6,37 \pm 0,34$ & 0,190 & $-1,773$ \\
schirmer & $25,63 \pm 8,28$ & $22,52 \pm 10,29$ & 0,076 & $-2,574$ \\
Endotel say1 & $204,25 \pm 56,59$ & $186,44 \pm 57,34$ & $0,001^{*}$ & $-0,401$ \\
Endotel yoğ. & $2842,41 \pm 261,99$ & $2846,02 \pm 273,55$ & 0,689 & $-1,567$ \\
cv & $25,83 \pm 3,67$ & $27,66 \pm 7,87$ & 0,117 & $-1,212$ \\
heks.h. & $68,47 \pm 5,50$ & $67,13 \pm 4,62$ & 0,226 & \\
\hline
\end{tabular}

$\overline{p<0,05}$ anlamlı.mkk: merkezi korneal kalınlık, postk: arka keratometri, EndotelYoğ:endotel yoğunluğu, cv: değişkenlik katsayısı,Heks h:Hekzagonal hücre.

$\mathrm{K} 1$, K2, MKK ve endotel say1S1 değerlerinde kontakt lens kullanımı sonrası istatistiksel olarak anlamlı bir azalma olduğu görüldü $(p<0,05)$. Posterior K1 değerinde lens kullanımından sonra istatistiksel olarak anlamlı bir artış olduğu görüldü. Posterior K2, schirmer, değişkenlik katsayısı ve hekzagonal hücre oranında anlamlı bir fark görülmedi. 


\section{Tartışma}

Kornea saydam bir doku olması nedeniyle, görme fonksiyonunun oluşmasında büyük role sahiptir. $\mathrm{Bu}$ saydamlığının sürdürülebilmesi için korneada yoğun bir metabolik aktivite mevcuttur. Bu metabolik aktivitenin sağlıklı bir şekilde devam etmesi için oksijen gereklidir. Kontakt lens, korneada hipoksik bir ortam oluşturarak bu metabolik aktiviteyi olumsuz etkileyebilmektedir. ${ }^{1}$

Kontakt lens kullanımına bağlı gelişebilecek hipoksiyi en aza indirip, korneanın olumsuz etkilenmesini önlemek amacı ile günümüzde oksijen geçirgenliği yüksek olan silikon hidrojel kontakt lensler (SHKL) tercih edilmektedir. SHKL'de her ne kadar hipoksik etkiler minimale indirilse de, bu lensler yüksek moduluse sahip olmaları sebebi ile özellikle kornea periferinde kesintili ve düzensiz aköz faz oluştururlar ve kapak basincinı korneaya daha fazla yansitarak mekanik ve inflamatuar etkilenmelere yol açarlar. ${ }^{2,12} 2005$ y1lından itibaren yeni nesil silikon hidrojel lensler geliştirilerek moduluse bağlı bu olumsuz etkilerin azaltılması amaçlanmıştır. ${ }^{13}$

İlk nesil silikon hidrojel lensler (Balafilcon A, Lotrafilcon A) yeni nesil silikon hidrojellere göre (Galyfilcon A, Senofilcon A, Latrofilcon B, Comfilcon A) düşük su içeriğine ve yüksek moduluse sahiptir. Yeni nesil lenslerin su içeriği arttığı için oksijen geçirgenliği ve modülüsü düşüktür. Kullanımı daha konforludur. ${ }^{13}$

Çalışmamızda ilk kez kontakt lens kullanmaya başlayan hastalardaki korneal değişimleri incelemeyi amaçladık.

Çalışmamızda kontakt lens kullanımında literatürde de yer aldığı gibi, kadınlar ve gençler ağırlıktaydı. ${ }^{14}$ Estetik kaygı, kozmetik merak ve el becerisi gereksinimlerinden dolayı kontakt lensler bu grupta daha fazla tercih edilmektedir.

Silikon hidrojel lensler, yüksek modülüse sahip olması ve su içeriğinin düşük olması nedeni ile konjonktiva ve korneaya indentasyon etkisi yaparak, santral korneal düzleşmeye ve epitel lezyonlarına yol açmaktadır. Epitelyal indentasyon etkisi lensi kaldırdıktan sonra görülen postlens debrisler musin topları veya lipid tıkaçları şeklinde görülmüştür. ${ }^{15} \mathrm{Bu}$ mekanik etkilerden dolayı kontakt lensler korneal kalınlık ve kurvatür değişikliklerine neden olabilmektedir. ${ }^{16}$

Kontakt lens kullanan olgulardaki topografik değerleri başlangıç değerleri ile kıyasladığımızda K1, K2, MKK değerlerinin azaldığını posterior $\mathrm{K} 1$ değerinin arttığını gördük. Gonzalez-Meijome ve ark. silikon hidrojel lens kullanan hastalarda ön kurvatürde 3.ay takibinde maksimum olan düzleşmeyi, sonraki 9. ayda ön kurvatür değerlerinin tekrar arttığını ve lens kullanmayı bıraktıktan 3 ay sonra ön kurvatür değerlerinin başlangıç haline geldiğini gözlemlemişlerdir. ${ }^{15}$ Aynı çalışmalarında korneal kalınlıkta da 12. ayda maksimum olan bir incelme gözlenmiştir. Tyagi ve ark. yapmış olduğu çalışmada silikon hidrojel lenslerin ön kurvaturde genel olarak düzleşmeye, arka kurvaturde de dikleşmeye yol açtığ gösterilmiştir. ${ }^{17}$

Bizim olgularımızın \%89,9'u ilk nesil silikon hidrojel lenslere göre düşük modülüslü yeni nesil silikon hidrojel lensler kullanmaktaydı. Buna rağmen ön kurvatürdeki düzleşme ve merkezi korneal kalınlıkta incelme olması lenslerin mekanik etkilerinin tamamen önlenemediğini göstermektedir. Arka kurvatürde dikleşme olması ise mekanik etkilere bağlı olmaksızın kornea mimarisinin etkilenebileceğini düşündürmektedir. Belki bu etki lensin oksijen geçirgenliği ile ilgili olabilir.

Kontakt lens kullanımı, gözyaşı film tabakasını ikiye bölerek buharlaşmayı artırır. Korneal hassasiyetin azalmasina sebep olarak lakrimal bezin baskılanması sonucu kuru göze neden olabilir. ${ }^{18}$ Çalışmamızda lens kullanan hastalarda schirmer testinde istatistiksel olarak anlamlı olmayan bir azalma olduğunu gördük. Schirmer testi kolay uygulanabilirliği nedeni ile tercih edilmiştir. Fakat güvenilirliği gözyaşı kırılma zamanı, gözyaşı hacmi ölçümü ve semptom sorgulamasına göre düşüktür. ${ }^{19}$

Speküler mikroskopi bulgularında sadece endotel sayısinda anlaml bir azalma olduğunu gördük. Korneal hipoksi ve stres; 
pleomorfizm, polimegatizm ve endotel hücre yoğunluğunun azalmasını tetikler. ${ }^{20}$

Ketessy ve ark. hidrojel lens kullananlarda endotel sayısinda istatistiksel anlaml olmayan bir azalma bulmuşlardır. Silikon hidrojel lens kullananlarda hücre yoğunluğunda ilk 1 ayda azalma sonrasında 2 yıla kadar artış ve 3. yılda tekrar azalma gözlemlemişlerdir. ${ }^{20}$ Lotrafilcon B kullananlarda hekzagonal hücre yüzdesinde 1 . ayda artış gözlemlenmiştir. Başka bir çalışmadada hücre dansitesi ve hekzagonal hücrelerin, 5 y1l üzeri kullanımda istatistiksel olarak anlamlı azaldı ğı görülmüştür. ${ }^{21}$

Robert ve ark., Balofilcon A, Lotrafilcon A, Senofilcon A kullanan hastalarda ortalama merkezi korneal kalınlık arasında belirgin farklılık izlememiștir. ${ }^{22}$ Tyagi ve ark. bizim çalışmamıza göre $\mathrm{dk} / \mathrm{t}$ ve modülüs değerleri daha düşük, su içeriği daha fazla olan kontakt lenslerle yapmış oldukları çalışmada, başlangıç değerlerine göre posterior korneada dikleşme olduğunu gözlemlemişlerdir. ${ }^{17}$

Çalışmamızı homojen gruplarda yaptık, fakat olgularımızın yaş aralığına bakacak olursak, üniversite öğrencisi çoğunlukta olduğu için lens kullanmaya başladıktan sonra kontrole gelenlerin sayısı yetersiz olmuştur. Olgu sayımızın yetersiz olması ve takip süremizin kısa olması çalışmamızın kısıtlayıcı faktörleridir.

\section{Sonuç}

Silikon hidrojel lenslerin yüksek oksijen geçirgenliğine rağmen korneanın fizyolojisi ve mimarisi hala etkilenmektedir. Son zamanlarda artan yumuşak kontakt lens kullanımı ve sonrasinda hastaların keratorefraktif cerrahi isteği, komplikasyonları önleyebilme ve beklentileri karşılayabilmek için bu lenslerin korneaya etkilerini bilmek faydalı olacaktır.

\section{Araştırmanın Etik Boyutu}

Çalışma öncesi 2018/9-10 karar sayılı üniversitemiz etik kurul onayı alınmıştır. Helsinki Bildirgesi ilkelerine uygun olarak yürütülmüştür.

\section{Bilgilendirilmiş Onam}

Çalışmaya dâhil edilen tüm hastalardan bilgilendirilmiş onam formunu alınmıştır.

\section{Yazar katkıları}

Araştırma ve/veya makalenin hipotezini veya fikrini oluşturmada A.S.K., verilerin düzenlenmesi ve raporlanmasında M.B. ve A.B. katkı sunmuşlardır.

\section{Çıkar Çatışması}

Yazarların herhangi bir çıkara dayalı ilişkisi yoktur.

\section{Araştırma Desteği}

Çalışmayı maddi olarak destekleyen kişi/kuruluş yoktur.

\section{Hakem Değerlendirmesi}

Diş bağımsız.

\section{Kaynaklar}

1. McCanna DJ, Driot JY, Hartsook R, Ward KW. Rabbit models of contact lens-associated corneal hypoxia: a review of the literature. Eye Contact Lens. 2008;34(3):160-5.

2. Dillahay SM. Does the level of available oxygen impact comfort in contact lens wear?: A review of the literature. Eye Contact Lens. 2007;33(3):148-55.

3. Temel A. Sert Kontakt Lensler (Materyal, Tasarım, Uygulama). MN Oftalmoloji. Ankara. 1994; 1: 21-24.

4. Pastewski BM, Lee AM. Contact Lens Care(Part 1). Am Drug. 1985; 192(11):117- 139.

5. Engle JP. Contact Lens Care. Am Drug. 1990; 201(1): 54-65.

6. TOD Eğitim Yayınları 4, Geleneksel Kontakt Lensler, Kontakt Lensler Ve Uygulanmas1, 1, İstanbul.2005;69-92.

7. Bergmanson JP, Chu LW. Corneal response to rigid contact lens wear. Br J Ophthalmol. 1982;66(10):667-75.

8. Schornack M. Hydrogel contact lens-induced corneal warpage. Contact Lens Anterior Eye. 2003;26(3):153-9.

9. Fonn D, du Toit R, Situ P, Vega J, Simpson T,Chalmers R. Apparent sympathetic response of contralateral non-lens wear igeyes after overnight lens wear in eyes after overnight lens wear in the fellow eye. Invest Ophthalmol Vis Sci. 1998(2);39336.

10. Holden BA, Mertz GW. Critical oxygen levels to avoid corneal edema for Daily and extended wear contact lenses. Invest Ophthalmol Vis Sci. 1984;25(10):1161-7.

11. Lee JS, Park WS, Lee SH, Oum BS, Cho BM. A comparative study of corneal endothelial Changes induced by different durations of soft contact lens wear. Graefes Arch Clin Exp Ophthalmol. 2001;239(1):1-4.

12. 12.Fleming C, Austen R, Davies S, Bolis S, Papas E, Holden BA. Precorneal deposits during soft contact lens wear. Optom Vis Sci. 1994;71(12):152-3.

13. 13.Iskeleli G, Karakoc Y, Ozkok A, Arici C, Ozcan O, Ipcioglu $\mathrm{O}$, Comparison of the efects of First and second generation silicone hydrogel contact lens wear on tear film osmolarity. Int. J. Ophthalmol.2013;6(5): 666-70.

14. Radaie SM, Hashemi H, Jafarzadehpur E, Yekta AA, Khabazkhoob M. Corneal Biomechanical Changes Following Toric Soft Contact Lens Wear. J Ophthalmic Vis Res. 2016; 11 (2): 131-135

15. Gonzalez-Meijome J. M, Gonzalez-Perez J, Cervin A, YebraPimentel E, Parafita M. A, Changes in Corneal Structurel with Continuous Wear of High-Dk Soft Contact Lenses: A Pilot Study. Optometry and Vision Science. 2003;80(6):440-6.

16. Ruiz-Montenegro J, Mafra CH, Wilson SE, Jumper JM, Klyce $\mathrm{SD}$, Mendelson EN. Corneal topographic alterations in normal contact lens wearers. Ophthalmology. 1993; 100 (1):128-34.

17. Tyagi G, Collins M, Read S, Davis B, Regional Changes in Corneal Thickness and Shape with Soft Contact Lenses. 
Optometry and Vision Science.2010; 87(8):567-75.

18. Chalmers RL, Begley CG. Dryness symptoms among an usselected clinica popularion with and without contact lens wear. Cont Lens Anterior Eye. 2006;29(1):25-30.

19. Glasson MJ, Stapleton F, Keay L, Sweeney D, Willcox MD. Differences in clinical parameters and tear film of tolerent and intolorent contact lens wearers. Invest Ophthalmol Vis Sci. 2003;44(12):5116-24.

20. Kettesy B, Vardai J, Berta A, ModisJr. L and Kemeny A. A survey of corneal changes caused by Daily wear silicone hydrogel contact lenses. Journal of Innovative Optical Health Sciences. 2015;8(6) 15500441-9.

21. Lee JS, Park WS, Lee SH, Oum BS, Cho BM. A comparative study of corneal endothelial changes induced by different durations of soft contact lens wear. Graefe's Arch Clin Exp Ophthalmol. 2001;239(1):1-4.

22. Steffen RB, Schnider CM. The impact of silicone hydrogel materials on overnight corneal swelling. Eye Contact Lens. 2007(33):115-20. 